\title{
REPRESENTAÇÃO POLÍTICA DE ATORES CÍVICOS \\ Entre a imediaticidade da experiência e discursos de justificação*
}

\section{Rousiley Maia}

$\mathrm{Na}$ sociedade contemporânea, complexa e pluralista, grupos de naturezas distintas - pobres, feministas, grupos étnicos, gays e lésbicas, pessoas com deficiência - experimentam diferentes tipos de identificação e diferenciação e, consequentemente, distintas formas de subordinação social, constrangimento institucional e depreciação cultural. Esses grupos vêm demandando crescente reconhecimento social e legal e a formulação de políticas públicas

* Uma versão anterior deste artigo foi apresentada no III Congresso da Compolítica realizado na Universidade Católica de São Paulo, entre 9 e 12 de dezembro de 2009. Agradeço as contribuiçóes de Mauro Porto, Ricardo F. Mendonça, dos participantes do GT "Comunicação e Democracia" e dos pareceristas anônimos da $R B C S$. Este trabalho faz parte do projeto de pesquisa "Mídia e sociedade civil no Brasil: lutas por reconhecimento e por questôes de interesse comum", com financiamento da Capes, CNPq e Fapemig.

Artigo recebido em 09/07/2010

Aprovado em 16/05/2011 mais favoráveis. Para a consecução de uma política democrática, muitos autores defendem a importância da participação desses grupos não só na esfera pública, mas, também, em decisões coletivas nos arranjos institucionais políticos (Habermas, 1997; Dahl, 1998, pp. 37-38; Fung e Wright, 2003; Fung, 2004, 2007; Young, 2000, p. 23). Neste artigo, retomo a discussão corrente sobre possibilidades democráticas de representação na esfera civil, que ocorrem por afinidades de ideias ou por adesão a uma determinada causa comum, e exploro o problema da legitimidade da representação informal. Neste caso, a dificuldade não é só a de definir quem fala em nome de quem na esfera civil, mas, ainda, a de definir o tipo de reconhecimento que os indivíduos e os grupos representados almejam, especificando os melhores meios para aliviar o sofrimento ou superar as injustiças.

Teóricos da democracia têm dado cada vez mais atenção a novos tipos de representação não 
eleitoral na esfera civil e a arenas inovadoras de julgamento político (Keck, 2004; Philips, 1995; Dryzek e Niemeyer, 2008; Urbinati e Warren, 2008; Saward, 2006, 2009). De modo geral, esses autores têm argumentado acertadamente que nem sempre indivíduos e grupos que sofrem injustiças possuem a motivação, os recursos ou as capacidades necessárias para expressar seus anseios ou especificar o que é preciso para se obter justiça em um determinado contexto. Usualmente, a maioria das pessoas não são politicamente ativas numa base permanente, e questôes de identidades ou de interesse comum são politizadas por algum subsetor desses grupos (Philips, 1995; Young, 1990, 2000; Dovi, 2002; Mansbridge, 2003, McBride, 2005). Além disso, pessoas em desvantagem podem não usufruir das condiçôes mínimas que lhes permitam ter autonomia individual e política; sofrem de destituição extrema, vulnerabilidade, opressão e ausência de liberdade (Sen, 1999; Souza, 2006; Bohman, 2007b). Esperar que elas "conquistem a própria voz", para conferir autenticidade e legitimidade às suas demandas, ou, então, esperar que se engajem em movimentos de contestação na esfera pública para processar seus projetos emancipatórios, pode ser um modo de relegar esses sujeitos à própria sorte, deixando inalterado o status quo.

Nesse sentido, grupos que abraçam certas causas e dizem representar e agir em nome de outros exercem um papel fundamental na política democrática (Urbinati, 2000; Castiglione e Warren, 2005; Lavalle, Houtzager e Castello, 2006; Avritzer, 2007; Saward, 2006, 2009, 2010). Organizaçôes e indivíduos - sem terem sido eleitos ou indicados, sem terem participado de fóruns deliberativos com os próprios interessados - reivindicam representar interesses e anseios e agir em nome de mulheres, grupos étnicos, grupos com deficiência, gays e lésbicas, pobres, animais, em prol do meio ambiente. Diversos autores defendem que o que se representa, neste caso, são "perspectivas", ${ }^{1}$ discursos ou anseios e não pessoas, como ocorre convencionalmente mediante atos de autorização pela via eleitoral, por delegação ou por representação baseada na confiança (Philips, 1995; Young, 2000; Dryzek e Niemeyer, 2008; Saward, 2006, 2009, 2010; Bohman, 2007a). Porta-vozes de coletividades, gru- pos de advocacy ou empreendedores morais têm afi nidade ou se identificam com a situação vivida por aqueles sujeitos e reivindicam (Saward, 2006) ${ }^{2}$ a representação de seus interesses.

Essa solução, contudo, não parece plenamente satisfatória e suscita vários problemas. Primeiro, o discurso em nome de outros pode se tornar meramente formal, vazio, ou, mesmo, constituir-se em novas fontes de alienação e opressão. Segundo, o julgamento sobre as demandas de representação é diverso, podendo partir de uma só voz, de grupos de advocacy, dos media, de representantes eleitos ou de um grande número de atores oriundos ou não da política institucional. Assim, as práticas que tornam a representação democrática e legítima precisam, elas mesmas, serem esclarecidas.

Este artigo tem por objetivo explorar os problemas que envolvem a legitimidade em práticas de representação informal. ${ }^{3} \mathrm{O}$ texto está organizado em três partes. Primeiro, procuro destacar a importância de considerar seriamente a experiência cotidiana de pessoas afetadas por diferentes formas de injustiça para construir formas de representação legítima. Defendo, tomando como base a teoria do reconhecimento, particularmente nos moldes de Honneth, que uma identificação bem-sucedida de maus tratos e violência, privação de direitos e exclusão ou, ainda, degradação e ofensa não pode prescindir da experiência, sofrida necessariamente na primeira pessoa. Em segundo lugar, discuto que a experiência subjetiva, apesar de constituir uma fonte insubstituível e necessária de inteligibilidade da injustiça, não pode se tornar uma fonte confiável de justificação na esfera pública. Para tanto, é preciso criar discursos abstratos e gerais de justificação ${ }^{4}$ que possam, inclusive, serem representados politicamente nos âmbitos legislativo e executivo. A representação legítima pressupõe um processo de feedback contínuo entre as experiências subjetivas e os discursos abstratos de justificação. Defendo o argumento de que a legitimidade deve buscada, sobretudo, mediante práticas discursivas contínuas. Em terceiro, analiso diversas formas de representação que se sobrepóem na esfera civil, ressaltando que elas não ocorrem de forma paralela ou alternativa aos canais tradicionais da política. Defendo que, 
para que a representação extraeleitoral seja eficaz e gere efeitos democráticos na organização da vida social, é preciso supor uma congruência entre a representação de natureza eleitoral e aquela informal. Nesse sentido, este artigo busca ampliar e aprofundar o nosso entendimento da legitimidade da representação não eleitoral como um processo contínuo, complementar à representação política formal.

\section{A relação entre experiência e representação não eleitoral}

Discussões correntes sobre o que "torna a representação democrática" e sobre eventuais lacunas na fundamentação normativa da democracia representativa (Urbinati, 2000, 2006a e b; Young, 2000; Mansbridge, 2004) devem levar seriamente em consideração que qualquer democracia que seja defensável numa base ética precisa tomar os indivíduos não como "receptores de justiça", mas, em vez disso, como "agentes de justiça” (Forst, 2007, p. 300; ver também Gutmann, 2003, p. 29). Isso implica entender os sujeitos como moral e politicamente autônomos e potencialmente capazes de codeterminar como querem viver a própria vida; decidir o que é importante e o que é secundário para superar os obstáculos ou as dominações que restringem suas vidas, de forma arbitrária ou injustificável. Questões sobre definiçōes de bem viver não podem ser respondidas, tanto do ponto de vista teórico de crítica social como do ponto de vista prático, por cientistas sociais exclusivamente ou por agentes administrativos encarregados de implantar políticas públicas, ainda que virtuosos, competentes e bem intencionados.

Teóricos do reconhecimento têm se esforçado em construir uma perspectiva normativa para mostrar a lógica moral dos conflitos sociais, a qual é anterior a qualquer atividade de representação. Particularmente Charles Taylor (1994) e Axel Honneth (1995, 2003) deixam-nos sensíveis para apreender a "dimensão diária dos sentimentos morais de injustiça”, "o sofrimento e a miséria causados institucionalmente", que existem prévia e independentemente de sua articulação por um movimento social
(Honneth, 2003, pp. 115-116). Aquém da soleira da esfera pública - entendida como locus da troca argumentativa sobre questôes de interesse comum -, há um estrato de "sofrimento pré-político", reivindica Honneth, o qual serve como base do que "é" ou o que "deve se tornar" questōes de interesse comum. $\mathrm{O}$ autor toma essa dimensão como referência empírica tanto para uma teoria moral como para a crítica social.

A teoria do reconhecimento de Honneth, calcada na atualização dos insights de Hegel por intermédio da psicologia social de G. H. Mead, propõe que a integração social opera através de formas de reconhecimento mútuo e que os sujeitos buscam, partindo de uma luta intersubjetiva, ampliar as condições necessárias para autorrealização individual. Construído sob uma concepção formal da vida ética, o quadro teórico de Honneth preconiza que nós não apenas "desejamos" reconhecimento, mas "precisamos" de múltiplas formas de reconhecimento, a fim de construirmos nossas identidades de modo íntegro e positivo: respeito na esfera legal, para que possamos perceber a nós mesmos como membro de uma comunidade de direito; estima na esfera social para que possamos nos sentir valorizados por nossas contribuiçōes particulares à sociedade; cuidados nas relações afetivas próximas, a fim de que possamos adquirir autoconfiança. A ausência de reconhecimento afetaria nossa capacidade de agir, dificultando nos tornarmos aquilo queremos ser, ou seja, a realização do tipo de vida que desejamos para nós mesmos (Honneth, 2003, p. 173; Anderson e Honneth, 2005). Apesar da diversidade das experiências de desrespeito, desprezo e humilhação, Honneth defende que todas elas têm um "centro" normativo (Honneth, 2003, p. 131): todas resultam de uma violação das expectativas de reconhecimento - expectativas essas que se constituem fonte motivacional do descontentamento social e da resistência.

A abordagem de Honneth vem suscitando um intenso debate, e sendo alvo de muitas críticas. ${ }^{5}$ Com base no conceito diferenciado de reconhecimento, Honneth busca mostrar que a experiência de injustiça social sempre corresponde à sustentação das expectativas que são tomadas como um reconhecimento legítimo. Como produto da for- 
mação social e do desenvolvimento histórico, os princípios de reconhecimento "produzem referência para que os sujeitos possam razoavelmente argumentar que as formas existentes de reconhecimento são inadequadas ou insuficientes e precisam ser expandidas" (Idem, p. 143). Os sujeitos e os grupos estariam, portanto, profundamente implicados em lutas intersubjetivas por reconhecimento. ${ }^{6}$

Em seu conhecido debate com Axel Honneth, Nancy Fraser, em vez de partir da noção de autorrealização para construir um conceito de justiça, propõe a norma da "paridade participativa" na vida social, a qual deve proibir tanto "formas e níveis de dependência econômica e desigualdade que impedem participação paritária" como "normas institucionalizadas que sistematicamente depreciam algumas categorias de pessoas e qualidades" (2003, p. 36). Propondo uma guinada da ética para a moral, a autora defende a paridade participativa como uma regra normativamente vinculante para todos aqueles que concordem em seguir os termos justos da interação, sob as condições do pluralismo valorativo (Fraser, 2001, p. 27).

Não tratarei aqui da acirrada disputa entre Honneth e Fraser - e demais interlocutores - sobre a dicotomia entre "reconhecimento" e "redistribuição" e de diferentes categorias de reconhecimento. Para os propósitos de minha argumentação, interessa apontar que qualquer luta por reconhecimento - independentemente do que ela significa ou demanda em um dado contexto - sempre implica complexas relaçôes com a esfera pública e com o juízo coletivo. Nas lutas para expandir as relações sociais de reconhecimento (nas esferas privada, legal e social), como propõe Honneth, há um movimento constante para estabelecer o significado dos princípios de reconhecimento, sobre o modo apropriado de sua interpretação e aplicação (Honneth, 2003, p. 186). Também a norma de "paridade participativa", como propõe Fraser, não é transparente e autoevidente e, portanto, não pode ser aplicada como um procedimento de decisão. Em vez disso, está sempre sujeita à interpretação e à contestação, e, como a própria autora reconhece, "deve ser aplicada dialógica e discursivamente, por via de processos de debate público" (Fraser, 2003, p. 43).
A teoria do reconhecimento admite como necessária a articulação entre diferentes domínios do reconhecimento, mas permanece silenciosa sobre as práticas de representação política. Honneth afirma que: "Quão mais bem-sucedido for um movimento social em chamar atenção da esfera pública para o sentido negligenciado de suas características e habilidades que eles [membros de um grupo] representam coletivamente, maiores serão as chances [...] de elevar a estima de seus membros" (1995, p. 127). Contudo, Honneth não esclarece como as lutas por reconhecimento são transferidas para o domínio público ou para o chamado nível político-institucional formal. Fraser incorporou recentemente a representação como uma terceira dimensão em seu quadro teórico, entendendo a dimensão política como necessária para tratar as tomadas de decisão coletiva e para problematizar os domínios em que ocorrem as lutas sobre distribuição e reconhecimento. ${ }^{7}$ Contudo, a autora também não explicita como e por que a representação é importante para o processo de expressão pública, para mediação da opinião e para a formação da vontade política. Diversos autores, como já apontado, entendem a representação política como um processo contínuo de "produzir e receber, aceitar e rejeitar demandas - durante, entre e externamente aos ciclos eleitorais" (Saward, 2010, p. 36, ver também Urbinati, 2000, 2006a). Antes de indagar sobre o potencial de pessoas não eleitas serem, em algum sentido, representantes democráticos legítimos, devo esclarecer alguns aspectos importantes da representação informal.

Primeiro, líderes de movimentos sociais ou representantes de associações voluntárias podem ser vistos como tradutores (Alexander, 2006, p. 229; Melucci, 1996, p. 73; Habermas, 1997, p. 33). Buscam, de um lado, captar sentimentos de injustiça e discursos expressivos de autoentendimento ou interpretação de necessidades, vivenciados nos contextos cotidianos por sujeitos que sofrem de opressão, humilhação, exploração etc. e articulá-los numa linguagem pública, isto é, passível de ser compreensível aos demais (Maia e Fernandes, 2002; Hobson, 2003; Mendonça, 2008; Garcês e Maia, 2009). Nem sempre o vocabulário para que certos sofrimentos e certas reivindicações sejam 
expressos está disponível. Um novo vocabulário, portanto, precisa ser criado, a fim de problematizar o que antes não era reconhecido como problema, no contexto social. Novas regras de reconhecimento não podem ser criadas ex-nihilo, da noite para o dia. Particularmente em casos em que não há direitos garantidos, algo moralmente relevante, porém ainda não tematizado, precisa ser mostrado, revelado como injustiça enraizada nas regras de convivência ou nos arranjos institucionais mais gerais da sociedade.

Em segundo lugar, a representação pode ser vista, conforme Urbinati apontou, como um veículo para associação dos indivíduos, mediante um complexo processo de união e desunião entre eles, que os projeta para uma perspectiva orientada ao futuro (Urbinati, 2000, 2006a). A representação constitui "um filtro compreensivo" que refina a pluralidade de aspirações, opiniões e perspectivas de um dado grupo e carrega consigo uma dimensão idealizadora que transcende o aqui e o agora, por meio de uma perspectiva do dever ser (Urbinati, 2000, p. 760). Entendida no contexto da sociedade civil, a representação ajuda a despersonalizar reivindicaçōes e opiniōes e a vocalizar uma concepção comum de injustiças experimentadas e de possíveis soluçôes. Somente em nome de um "coletivo" é possível projetar experiências comuns no conjunto mais amplo de relaçóes da sociedade (Melucci, 1996, 2001; Benhabib, 2002; Young, 1990, 2000). Somente com um discurso relativamente coerente é possível articular o descontentamento e nomear injustiças, como dificuldades ou problemas comuns causados pelos arranjos institucionais ou pelos padrōes culturais.

Em terceiro lugar, são líderes de movimentos sociais ou de associaçôes coletivas, intelectuais ou empreendedores morais em prol de certas causas, os que desenvolvem recursos e uma estrutura de oportunidades com intuito de chamar a atenção pública para problemas previamente negligenciados e para exercer influência contra ou dentro do Estado. Associações, constituídas de diferentes modos, encontram múltiplos caminhos para a representação política no sentido de organizar resistência (demonstrações, protestos, boicotes, desobediência civil etc.), estabelecer a colaboração com outros grupos, sustentar o debate na esfera pública e operar como auxiliares ou parceiros em programas do governo (Warren, 2001).

Para nossos propósitos, interessa destacar que porta-vozes de associações voluntárias, líderes de movimentos sociais e empreendedores morais são particularmente capacitados para politizar a esfera social e trazer a pluralidade e a diferença a público. Isso se dá na medida em que eles buscam expressar publicamente, em fóruns diversos, o que consideram aspectos importantes de certas identidades, reivindicam proteção a determinados modos de vida ou à conservação de determinadas culturas, ou se empenham em lutar coletivamente contra o que consideram desrespeito ou outras formas de injustiça. Por exemplo, se considerarmos os media de massa como um dos fóruns com maior visibilidade na sociedade contemporânea, é fácil perceber que, ao lado de representantes políticos e especialistas, são pessoas que gozam de alguma proeminência - com distintos graus de reconhecimento público de sua autoridade, competência ou confiabilidade - que são convidados a expressarem suas ideias e opiniões e a se engajarem em uma conversação pública sobre o sentido dos eventos (Habermas, 2006, p. 417; Peters, 2007, pp. 126-127; Maia, 2008).

Em síntese, líderes de movimentos sociais, advogados em prol de certas causas e empreendedores morais são essenciais para traduzir problemas, para construir processos de união entre os cidadãos, para sustentar o debate na esfera pública e exercer influên cia nos corpos políticos institucionalizados. A representação informal pode se deter em assuntos específicos e estender demandas de representação através das fronteiras locais, nacionais e transnacionais, transcendendo distritos eleitorais particulares e os territórios do Estado-nação. Apesar de representantes não eleitorais poderem potencialmente produzir muitos efeitos democráticos na organização da vida social, a questão de como eles são autorizados e como eles prestam contas àqueles a quem dizem representar permanece.

Esta questão já recebeu atenção de diversos teóricos da democracia. Considerando a natureza dos agentes representantes, Urbinati e Warren (2008, p. 404) oferecem uma lista de mecanismos de autorização de representação não eleitoral. ${ }^{8}$ Saward 
(2009, pp. 10-14; 2010, pp. 95-102) especifica um conjunto de demandas de representação, que invocam diferentes fontes de autoridade e de justificaçôes. ${ }^{9}$ A lista de possíveis modos e mecanismos de accountability é também extensa no domínio não eleitoral (Urbinati e Warren, 2008; Goodin, 2008, pp. 167-174). ${ }^{10}$ Diversas formas de representação (e modos de gerar accountability) interagem entre si e podem gerar conflito na sociedade. Defendo o argumento de que múltiplos corpos de monitoramento e práticas de accountability podem ajudar a aproximar práticas de representantes informais e o julgamento daqueles representados, mas é principalmente em suas interaçôes comunicativas e deliberativas que a geração da legitimidade deve ser buscada. ${ }^{11}$ À luz de normas e funçōes gerais da representação democrática, explorarei, nas seções seguintes, a complicada e frequentemente tensa prática discursiva de representantes informais, diante dos grupos que dizem representar e do conjunto de cidadãos na sociedade.

\section{Coletividades, audiências e representação política: "nós" quem?}

Os grupos nunca são objetos de representação como unidades ou como agregados homogêneos, já que são constituídos por indivíduos com diferentes e complexas experiências, moldadas por alguma consciência compartilhada de pertencimento. Nesse sentido, identidades coletivas ou identidades de grupos tornaram-se termos altamente disputados no debate contemporâneo. "Nenhuma identidade de grupo singular nem todas as identidades de grupo tomadas em conjunto compreendem completamente a pessoa" (Gutmann, 2003, p. 2). Os indivíduos apresentam múltiplas identificações e diversos laços de pertencimento, sendo que distintas formas de diferença e subordinação perpassam de uns para outros (Fraser, 2003, p. 57). Os interesses coletivos não podem ser assumidos como dados. Autores que trabalham com movimentos sociais ou a política da identidade, seguindo a linha do construcionismo social, apontam que a constituição de um nós - com o qual é preciso se identificar para dar consistência e continuidade à ação coletiva - é algo sempre em processo de construção (Touraine, 1978; Melucci, 1996, 2001; Scherer-Warren, 1996; Benhabib, 2002).

Para desenvolver meu argumento, é preciso destacar que um grupo de pessoas precisa reconhecer aquele que fala ou age em seu nome como um representante (Rehfeld, 2009, p. 5). No entanto, os membros de uma audiência podem ou não ver a si mesmos como pertencentes àquela coletividade mencionada. Sigo aqui a definição pragmática de audiência, proposta por Saward, como um grupo que recebe (ouve, vê ou mostra-se ciente) de uma reivindicação, e cujos membros podem "aceitar, rejeitar ou ignorar a reivindicação” (2009, p. 3). Apesar de endossar a necessidade de operar com um sentido fluido e dinâmico de audiência, defendo que, para efeitos de clareza teórica e acuidade empírica, é preciso discutir as práticas discursivas e o problema da legitimidade não eleitoral sob duas perspectivas: a) interna à coletividade, isto é, sob a perspectiva daqueles que se reconhecem como parte do grupo mencionado e b) externa à coletividade, isto é, sob a perspectiva daqueles que não se reconhecem como parte do grupo. Esta distinção não implica em uma visão essencializada do grupo, a partir da suposição de que os vínculos dos indivíduos seriam dados, fixos ou que existiriam de modo pré-político. Entendida a partir de uma abordagem construcionista e pragmática, esta distinção é importante para esclarecer como uma "demanda representativa" pode ser justificada discursivamente diante de diferentes audiências (internas e externas ao grupo) e, ainda, para evidenciar as interdependências entre essas audiências. Nas seções seguintes, tratarei da legitimidade da representação a partir destas duas perspectivas.

\section{$A$ representação a partir da dimensão interna ao grupo}

As relações de representação são complexas tanto no plano conceitual como na prática (Pitkin, 1967, 2006). Mecanismos de representação não agregam simplesmente as preferências de um dado grupo, mas são, também, formadas e transformadas pelos agentes desta coletividade. As características da relação da representação são constituídas por um 
processo político, com base em conflitos e ações coletivas. ${ }^{12}$ Pensada a partir da dimensão interna ao grupo, a representação pressupõe um nexo entre a percepção das pessoas que vivem ordinariamente situações de maus tratos, violência, denegação de direitos, ostracismo social ou exploração e o que real mente conta como injustiça, o que é considerado válido e justificável diante dos demais.

Assim sendo, não basta somente expressar reivindicações ou torná-las inteligiveis, mas é preciso construir justificação para que as reivindicações possam ser potencialmente aceitas. Ainda que os indivíduos e grupos apresentem certas demandas como necessárias à autorrealização ou à participação igualitária, eles precisam construir padrōes adequados de verificação para que suas reivindicaçôes sejam submetidas à avaliação pública, diante de todos aqueles que fazem parte de uma comunidade política.

Os representantes de movimentos sociais e porta-vozes de determinadas causas, a fim de construírem um discurso público, vocalizarem e defenderem interesses, precisam filtrar e separar a parcialidade irredutível das identidades individuais, enquadrar desejos, valores e juízos, através de uma linguagem pública, compreensível e aceitável aos demais. Conforme Urbinati aponta, a representação "transcende a imediaticidade das experiências e dos interesses [dos indivíduos], e educa seus julgamentos políticos sobre suas próprias opinióes e sobre as opiniões dos outros" (2000, p. 760). Goodin também propõe que os representantes, ao se engajarem numa comunicação pública, sempre têm as audiências em mente e, por isso, estarão, "ao menos estrategicamente, tentados a dar a entender que seus planos são bons para o público em geral, assim como para os seus próprios defensores" (2008, p. 199). Por isso mesmo, é altamente improvável que qualquer discurso - por mais bem-intencionado e competente que seja - contemple a diversidade das aspirações e dos interesses em jogo. É altamente improvável que o vocabulário através do qual a demanda é expressa seja plenamente adequado àquilo que se quer ou que necessita ser reconhecido.

Ao menos idealmente, cabe aos representados dizer "sim" ou "não" às demandas de representação expressas por representantes ou, ainda, oferecer abordagens alternativas (Saward, 2009, 2010).
Em grupos que buscam reconhecimento, este não é, por certo, um processo fácil, quando o entrecruzamento entre condiçōes sociais e estruturas institucionais reproduzem relações de poder e obstruem a reflexão crítica e a comunicação. $\mathrm{Na}$ medida em que os cidadãos representados precisam aceitar as demandas de representação e apoiá-la do ponto de vista da primeira-pessoa, a representação capacita o escrutínio crítico. Vista desse modo, a representação ajuda a desencadear a reflexão crítica, para que os membros do grupo reflitam por si mesmos, falem de suas necessidades factuais e defendam seus julgamentos, trazendo à luz especificidades que precisam ser percebidas e consideradas. Esse é um processo circular. Pessoas que atuam como representantes de associaçóes ou advogados de uma determinada causa, ao reivindicar falar em nome de ou agir simbolicamente no lugar de outras pessoas, motivam a reflexão, a critica e o julgamento, por afetados e interessados, sobre se suas identidades e seus interesses, se suas ideias e seus discursos são efetivamente reconhecidos e adequadamente expressos (Philips, 1995; Young, 2000). Frequentemente, os participantes do grupo discordam sobre prioridades, interpretação e aplicação de normas, e produzem fragmentação ao infinito sobre os detalhes do bem comum.

Entender a representação sob a perspectiva reflexiva e discursiva faz ver que a representação ajuda a produzir um distanciamento cognitivo entre pessoas e argumentos, entre quem e o que está sendo representado. ${ }^{13}$ Castiglione e Warren mostram que alguns interesses e valores são formados em resposta à atividade de representação, a qual pode funcionar para "evocar interesses latentes, despertar a consciência ou superar problemas da ação coletiva" (2005, p. 20). Certos interesses e anseios não estão previamente formulados, mas, ao contrário, são constituídos durante a relação de representação. Assim, a experiência subjetiva, a partir do distanciamento produzido pelo processo reflexivo, torna-se um meio de resistência, de averiguação ou correção de discursos abstratos de justificação e pode, de tal modo, evitar que os conteúdos desses discursos se tornem vazios ou atuem como mais uma fonte de alienação (Kompridis, 2007, p. 281). Portanto, a experiência subjetiva deve permanecer como uma 
referência normativa importante para a contestação e a transformação dos discursos abstratos.

A representação democrática pressupõe congruência e resposta aos anseios dos representados. Desprovidos de atos iniciais de autorização, os representantes informais assumem obrigaçōes e deveres baseados não no medo de potenciais sanções, como é típico com os representantes eleitorais, mas, sobretudo, devido ao comprometimento moral (Dryzek e Niemeyer, 2008, p. 490; Goodin, 2008, p. 172). Os representantes são convocados a dar respostas, explicações e justificações sobre suas demandas, ao passo que representados se engajam em questionamento, crítica e contestação.

Assim, representação informal requer também a construção de espaços e a sustentação de oportunidades para a troca de valores, pontos de vista e interesses (Mansbridge, 2004; Saward, 2006; Abers e Keck, 2008; Mendonça, 2008). Com efeito, os sujeitos que se identificam como pertencentes a um determinado grupo devem possuir a liberdade e a oportunidade de ter voz e chances para expressar aspectos valorizados de seus interesses e suas identidades (Bohman, 2007a), a fim de contestar falsas invocaçôes de "autenticidade" ou de "homogeneidade" e, assim, reformular demandas para acomodar novos anseios ou demandas que também podem ser defendidas com apelos a princípios, valores e bens. De tal sorte, ter a liberdade e a oportunidade de expressão não só para produzir a contestação como também para receber audição são requisitos tão necessários para a construção da representação legítima entre representantes informais e membros de grupos como em processos discursivos em fóruns formais do sistema político.

\section{A Representação a partir da dimensão externa ao grupo}

Nem todas as reivindicações e demandas podem ser legítimas ou aceitáveis moralmente. As demandas de determinado grupo afetam de modo intrincado outros grupos, numa teia complexa de relaçōes entre diferentes atores. As reivindicações para alterar a distribuição de status, de respeito ou de estima imbricam-se, de modo complexo, com a organização prevalente das relações de poder econômico, social e político. Assim sendo, os desafios a determinadas regras fundadas, por exemplo, no racismo, no sexismo ou no xenofobismo, frequentemente, implicam também demandas para alteraçôes em relaçôes atinentes ao poder econômico (tais como acesso à universidade, a emprego, a promoçōes etc.), à organização jurídica (tais como garantias de igual tratamento no casamento, acesso aos benefícios sociais etc.) ou ao poder político (tais como definiçôes de quais grupos contam e qual cota de representação cabe a eles na produção da decisão) (Tully, 2000, p. 471; Feldman, 2002). Assim, os coletivos ou os grupos identitários não podem ser a fonte última de valor em qualquer democracia preocupada com a igual consideração dos indivíduos. É por isso que as demandas de grupos devem estar abertas ao escrutínio público e devem ser justificadas diante de interesses concorrentes.

Todos os representantes ou aqueles que tomam decisōes que afetam outros, como Rehfeld apontou, "irão encarar trocas entre seguir a justiça ou seguir as preferências daqueles afetados por suas decisōes" (2009, p. 216). A representação legítima pressupõe a confrontação discursiva para elucidação recíproca entre os grupos reivindicantes e os demais grupos que alegam ser adversamente afetados. O debate crítico, na esfera pública, tem idealmente a função de processar o que conta como razoável e moralmente defensável, e, assim, distinguir entre reivindicações justificáveis daquelas que não são justificáveis. Expressôes de desejos ou necessidades por membros de grupos específicos precisam de certa maneira ser transformados em reivindicações de justiça, tais como as reivindicaçóes de que certas mudanças aumentarão as oportunidades para que os indivíduos possam legitimamente articular partes de sua própria identidade e aperfeiçoar o processo de inclusão social (Honneth, 2003, pp. 184185) ou proporcionar as condiçōes para avançar a "paridade participativa", sem introduzir ou exacerbar outras disparidades que não são defensíveis (Fraser, 2003, pp. 38-39).

A fim de avançar reivindicações que sejam negociáveis em termos dos padrōes públicos, porta-vozes de movimentos sociais, grupos de advocacy ou empreendedores morais precisam geralmente se engajar em "diálogos múltiplos" com diferentes atores (Tully, 
2000, p. 475): alguns se recusam até mesmo a escutar as demandas dos grupos reivindicantes; outros contestam essas demandas e defendem o status quo; outros podem se dispor a cooperar dialogicamente e a negociar em alguma medida, e outros, ainda, podem avançar demandas antagônicas.

$\mathrm{Na}$ vida real, as discussōes que têm lugar na esfera pública acontecem frequentemente em contextos distantes dos ideais, em termos de equanimidade de oportunidades para expressão de demandas concorrentes, de reciprocidade de escuta, da consideração mútua entre as partes envolvidas etc. Há sempre diversos constrangimentos - pressóes de tempo, insuficiência de melhores informações, custos da decisão política e influências extradiscursivas. Há sempre assimetrias de oportunidades e de recursos entre aqueles que se engajam nas argumentaçōes e negociaçōes. Uma vez que as resoluçôes sempre abrigam elementos não consensuais e alguma forma de injustiça, todo consenso ou toda decisão majoritária é invariavelmente falível e, em princípio, passível de revisão (Tully, 2000; Benhabib, 2002; Bohman, 2007a). Como já apontado, os interesses e as demandas tendem a se transformar ao longo do tempo, diante da própria negociação, de novas descobertas ou novos conhecimentos (Gutmann e Thompson, 2004). Assim, a representação legítima pressupõe abertura a dissensos razoáveis e a disposição para dialogar com aqueles de quem se discorda, a fim de construir acordos sobre cursos de ação mutuamente aceitáveis ou para encontrar formas de convivência, preservando pluralismo de valor, crenças e preferências.

\section{Institucionalização da representação não eleitoral}

A constituição legítima da representação política na esfera civil pressupõe, como apontei, processos de diálogo e de trocas argumentativas recíprocas entre aqueles que vivenciam as experiências de injustiça e aqueles que dizem representar e agir em nome de outros. Sem que se articulem com as instâncias formais do sistema político, a representação informal e os processos de discussão pública ficam isolados do poder do Estado e das políticas gover- namentais (Feldman, 2002; Pinto, 2008; Loureiro, 2009). Assim, é preciso lidar com o problema da legitimidade e da representação não eleitoral a partir da complexa inter-relação existente entre a sociedade civil, a esfera pública e as instituiçōes formais de uma democracia estabelecida.

As dicotomias entre "representação por pessoas" versus "representação através do discurso" ou "representação formal" versus "representação informal" precisam ser relativizadas neste ponto de minha argumentação, a fim de captar suas interdependências. Diferentes desenhos de sistema eleitoral (baseados na pluralidade de membros singulares de um distrito ou na representação proporcional), distintas formas de autorização e modelos de governo geram formas diferentes de os representantes eleitos exercerem accountability, sendo algumas mais difusas e outras mais fortes (Mansbridge, 2003; Parkinson, 2006; Urbinati e Warren, 2008). Mansbridge mostrou de modo influente que, em diversas relaçôes de representação, as ideias que os representantes políticos, autorizados pela eleição, constantemente constroem sobre os representados não precisam ser guiadas por "critérios relativo a pares, apropriados para a representação promissória": "Eles podem ser deliberativos ao invés de agregadores [...] plurais ao invés de singulares" (2003, p. 515). Partidos políticos, apesar de serem vistos frequentemente como instrumentos de elites políticas em vez de veículos de participação, podem e devem transformar formas mais particulares de advocacy em demandas mais competitivas de interesse e bem comum e, assim, também estruturar o discurso público (Urbinati, 2000, p. 778, 2006a, pp. 37-38).

Nadia Urbinati (2000, 2006a e b), apesar de não se colocar entre os autores deliberacionistas, contribui para desenvolver esse problema, ao pensar a representação como um conjunto mais amplo de julgamento político, que envolveria outras temporalidades e outras formas não eleitorais de representação, num contínuo da ação política. Ao entender que decisões são construídas ao longo do tempo, com intervalos entre os diversos momentos de decisão, ela defende que os representantes, diante da variedade de discursos trazidos à esfera pública pelos grupos de advocacia, veem-se instados 
a exercer a accountability de modo mais vigoroso: envolver-se em uma série de discussōes nas quais, de outra forma, não se engajariam ou justificar suas ações à luz das razões trazidas a público, e não por qualquer razão que pudesse, porventura, parecer conveniente.

A autora (2006a, p. 28), ao focalizar o poder negativo dos cidadãos que lhes permite "investigar, influenciar e censurar seus legisladores", não chega a incorporar em sua teorização formas de institucionalizar a representação da sociedade civil. Também Saward (2010) não aborda novos desenhos institucionais para aumentar a legitimidade política e sustentar a complementaridade desejável entre participação e representação. Governos e outras entidades têm progressivamente designado “representantes cidadãos” (Warren, 2008), isto é, formas de representação formalmente designadas, não eleitorais, em que os cidadãos são selecionados ou autoselecionados. Uma diversidade de experiências organizadas com "minipúblicos" - tais como os planning cells, citizens juries, deliberative pools, consesus conferences - contribuem para abrandar alguns problemas que acometem o debate disperso da esfera pública ${ }^{14}$ e ajudam a conferir um caráter formal à representação da sociedade civil (Avritzer, 2007, p. 454; Fung, 2004, 2007; Fung e Wright, 2003). Particularmente relevante para captar interesses não organizados e valores que carecem de atenção pública são experimentos como os do Chambers of Discourse, os quais visam representar não pessoas, mas, sim, discursos. ${ }^{15}$ Levar em consideração essas experiências permite explicar de modo muito mais específico, do que o modelo da deliberação na esfera pública ampliada, como o diálogo público afetará os representantes eleitos a se conectar com o poder estatal.

Cabe destacar também desenhos institucionais no campo das políticas públicas, em que há partilha de poder e a participação da sociedade civil é formalmente pressuposta pela lei, em experiências tais como as de conselhos gestores e do Orçamento Participativo (Wampler e Avritzer, 2004; Coelho et al., 2005; Baiocchi, 2005; Abers e Keck, 2008, Avritzer, 2009). Nesses arranjos, atores da sociedade civil, indivíduos ou porta-vozes de associações assumem um papel formal de representação e têm certa autoridade sobre normas, planos e, ocasionalmente, sobre o orçamento, nas suas áreas de atuação. Nesses casos, elementos tradicionais, não discursivos, de representação política imbricam-se com a advocacia e a representação discursiva (Avritzer, 2007, p. 459). Tanto a representação formal como aquela derivada da participação da sociedade civil podem operar simultaneamente em um mesmo ambiente.

Não faz parte dos propósitos deste artigo avaliar os méritos e as lacunas dos desenhos institucionais apontados brevemente acima. $\mathrm{O}$ interesse é ilustrar que os novos desenhos institucionais estabelecem vínculos variados entre representantes e representados e novas formas de produzir definições políticas, controle e fiscalização por parte dos cidadãos, para além do processo eleitoral. Ao passo que se devem admitir os inúmeros benefícios desses arranjos, como espaços descentralizados e dinâmicos, para estabelecer a complementaridade entre participação, julgamento político e representação, há de se destacar que todas as formas de representação são parciais e incompletas. Todos os tipos de representação informal possuem falhas. Representantes autoautorizados podem sempre introduzir desigualdades, e a ausência de obrigações do tipo principal-agente implica que suas decisões não podem ser vinculantes (Parkinson, 2006, p. 80; Urbinati e Warren, 2008, p. 405). $\mathrm{O}$ critério de proporcionalidade para compor os "minipúblicos" tende a marginalizar vozes minoritárias, e o estabelecimento de amostragem por quotas tende a reforçar pressuposições de que grupos específicos possuem uma natureza essencial (Dovi, 2002, p. 732; Parkinson, 2006, p. 97). O esforço para operacionalizar a noção de discursos para propósitos empíricos encontra o problema de como conhecer antecipadamente se a diversidade foi adequadamente identificada, e metodologias para selecionar os discursos dificilmente eliminam fatores de enquadramento. "Minipúblicos" selecionados randomicamente podem se tornar ferramentas que as elites utilizam para legitimar certas políticas (negligenciando a accountability eleitoral) ou para substituir formas mais amplas de julgamento e participação dos cidadãos (Urbinati e Warren, 2008, p. 406; Parkinson, 2006, p. 96). 
É importante reiterar a visão da representação como um processo reflexivo e discursivo no contínuo da ação política para aliviar esses riscos. Práticas de representação não podem alcançar legitimidade completa no sentido ideal, mas podem ser aperfeiçoadas. Trocas discursivas e a accountability mútua ${ }^{16}$-por vários meios, na esfera pública e através de corpos deliberativos estruturalmente institucionalizados - entre as elites políticas e os diversos públicos podem ter capacidade dinâmica para a autocorreção. É esse entendimento que proporciona esperança de que a representação não eleitoral possa contribuir para aproximar as demandas dos cidadãos e a vontade de seus representantes políticos.

\section{Conclusão}

Neste artigo, busquei explorar a importância da representação informal, não eleitoral, exercida na sociedade civil. Defendi o argumento de que a experiência imediata dos sujeitos é fundamental como fonte de inteligibilidade das injustiças. Ainda que experiências de maus tratos, violência, humilhação, degradação e ofensa estejam submersas em contextos da vida cotidiana, muitas vezes privadas de atenção pública, ou, mesmo, de reconhecimento social, elas são fonte necessária e insubstituível de inteligibilidade da injustiça. Tomando como base a teoria do reconhecimento, discuti que as experiências subjetivas de desrespeito, tal como propóe Honneth, podem ser entendidas também como fundamental fonte de resistência e motivação para diferentes lutas por reconhecimento. Contudo, não é possível situar o propósito da justiça apenas no sentimento dos oprimidos ou naquilo que eles reivindicam como importante e necessário para a autorrealização. A construção da reivindicação legítima resulta do julgamento coletivo, que escapa ao controle dos indivíduos ou dos grupos.

A representação informal, de origem extraeleitoral, ajuda a solucionar parcialmente o problema da construção e da defesa de reivindicações legítimas. Indivíduos e associaçóes que abraçam certas causas e dizem representar e agir em nome de outros são fundamentais para traduzir sentimentos de injustiça e discursos expressivos de autoentendimen- to numa linguagem pública; trazer problemas ou conflitos para que possam ser percebidos e considerados pelo público; contestar padrões hegemônicos e justificar reciprocamente, em práticas de debate público, "como" e "por que" determinadas demandas são legítimas, e, ainda, descortinar novas possibilidades de formular regras e organizar políticas públicas. A mudança social governada pela transformação dos padrões de reconhecimento exige processos de contestação e de troca argumentativa na esfera pública, devendo ocorrer tanto nos domínios informais como nos domínios formais de tomada de decisão no sistema político. Somente dessa forma é possível transformar padróes estabelecidos de legitimação pública ou de justificação, previamente considerados suficientes para a regulamentação institucional.

Deve-se ter em mente que os representantes da sociedade civil, ao lançarem luz sobre problemas ou questōes que demandam novo entendimento, podem tanto revelar como obscurecer determinados aspectos relevantes dos conflitos. Independentemente de quão informados ou bem-intencionados estejam, os representantes produzem discursos que sempre carregam consigo o risco de reconhecimento restrito ou distorcido, o qual pode provocar resistência e contestação. Todas as formas de representação, mesmo as mais fidedignas, são parciais, unilaterais e incompletas. Para constituir a representação de ideias ou discursos de modo legítimo, é preciso haver um feedback entre os discursos abstratos (necessários para "filtrar" e "generalizar" as experiências subjetivas) e as experiências subjetivas (necessárias para "testar" ou "corrigir" os discursos abstratos). Num processo circular, a experiência, atestando formas de desrespeito, marginalização e exploração, e os discursos abstratos de justificação estão sempre em choque e precisam se ajustar mutuamente mediante práticas dialógicas e discursivas.

A representação informal não é independente e nem alternativa à representação formal, mas possui um caráter duplo ao estabelecer uma interface com a sociedade e outra com o Estado. Se a organização da sociedade é pautada por obrigações legais, os processos de representação não podem se restringir aos contextos da esfera civil, da vida cotidiana, dos movimentos sociais ou dos media. É preciso propa- 
gar a tematização de injustiças na agenda política dos representantes eleitos, a fim de institucionalizar as demandas oriundas da sociedade civil. A luta dos sujeitos na vida prática, para processar o que significa reconhecer e ser reconhecido, não chega, a um estágio final, mas pressupõe contestação dinâmica. A representação informal precisa ser discursivamente criada e recriada em conjunto com afetados e interessados. De modo semelhante, a articulação entre a representação informal, extraeleitoral, e a formal pressupõe um processo contínuo de práticas discursivas e possui mais chances de ser aperfeiçoa$\mathrm{da}$ em sistemas que institucionalizam diversas formas de deliberação em arenas diversas de comunicação e controle, com vários níveis de organização.

\section{Notas}

1 Iris Young (2000) afirma que a representação de perspectivas e pontos de vista que emerge da posição diferenciada das pessoas no campo social é diferente da representação de interesses e opiniōes. Grupos marginalizados e oprimidos, por exemplo, não possuem as mesmas opiniōes políticas, mas, segundo a autora, a perspectiva delas condiciona seus interesses e suas opiniōes. Isso não oferece razões propriamente ditas, mas articula importantes diferenças de experiência que informam o julgamento de razóes mais ou menos persuasivas.

2 A fim de enfatizar que a representação é sempre processual, Michael Saward utiliza o termo "demandas representativas" (representative claims), isto é, "uma demanda de representar, ou que sabe que representa o interesse de alguém ou de alguma coisa" (2010, p. 42). A reivindicação pode ser expressa de diversos modos, tais como representar os interesses de uma pessoa, as necessidades de um país ou de uma região, ou, ainda, as necessidades da natureza. Pode-se também reivindicar a representação dos desejos dos correligionários etc.

3 Para tanto, adoto uma abordagem geral semelhante a de Dryzek que argumenta: "se alguma coisa (seja uma instituição, um valor, uma política, uma decisão ou uma prática) é legítima, então, isso significa que ela deve ser aceita como apropriada por aqueles a quem se aplica" (2010, p. 21). A aceitação deve ser concedida livremente por aqueles que conferem legitimidade; e as pessoas devem estar cientes do que está sendo reivindicado.
4 Sigo aqui a distinção proposta por Habermas entre "discursos de aplicação" e "discursos de justificação". Discursos de aplicação referem-se às situações em que juízes ou outros como eles decidem sobre casos específicos tomando como base normas já justificadas, e, assim, podem assumir uma imparcialidade (concebida como um distanciamento neutro). Já "discursos de justificação" referem-se às situações em que a validade geral da norma é buscada, sendo que se espera que cada participante do debate assuma a perspectiva interna dos outros afetados (o que é incompatível com a adoção da perspectiva da terceira pessoa). Cabe ressaltar que "normas que gozam de validade evidente [ $p r i-$ ma facie validity] permanecem abertas à interpretação futura, à luz de constelaçôes de situaçôes de aplicação não previstas" (Habermas, 1993, p. 37; cf. também pp. 35-38, 48-50).

5 Para uma abordagem crítica do debate entre Nancy Fraser e Axel Honneth, ver Thompson (2005, 2006) e Zurn (2003).

6 Embora não explore explicitamente problemas da ação coletiva, Honneth evidencia que a criação de um sistema de direitos e o estabelecimento de um horizonte cultural em que os cidadãos tenham oportunidades de virem a ser estimados pressupóem distintos tipos e níveis de ação coletiva (Honneth, 1995, pp. 206-208).

7 Fraser argumenta que a dimensão política é "necessária para problematizar tanto a divisão do espaço político em organizações ou em comunidades políticas como para problematizar a produção da decisão que aí ocorrem". A autora acrescenta que "a representação fornece o palco no qual as lutas por redistribuição e reconhecimento acontecem" (2007, p. 313).

8 Esses autores diferenciam agentes representativos em duas categorias: "autoautorizados" (self-authorized) e "cidadãos representantes" (citizen representatives) [Urbinati e Warren, 2008, pp. 403-406]. Mostram que a autorização em organizações voluntárias fundada em modelos de afiliação opera através de voz e voto, embora a maioria dos casos de autoautorização seja problemática por causa da ausência de autorização formal. Em experiências de "cidadãos representantes", a autorização ocorre via "procedimentos formalmente designados", por meio dos quais as pessoas são selecionadas ou se voluntariam para servir de representantes de outros cidadãos.

9 Saward proporciona o critério mais amplo por meio do qual a aceitabilidade democrática dos reivindicantes pode ser apreciada com base em: a) raízes arraiga- 
das, tais como a moralidade do grupo, as tradiçõos ou um consenso hipotético; b) expertise e credenciais especiais; e c) amplos interesses e novas vozes, tais como vozes daqueles que são sub-representados; vozes da rua provenientes de demonstrações populares maciças e tangíveis; amplos interesses derivados de similaridades entre representantes e pessoas representadas; stake holding; defesa de normas extraterritoriais e regras de autorrepresentação.

10 Em associações voluntárias, a accountability de representantes não eleitos pode operar por meio do monitoramento e de sanções concernentes à reputação dos membros do grupo; da avaliação por comitês; da apreciação pelos media ou por outros grupos da coerência entre a ação dessas associações e a missão professada em suas cartas de intenções e, por fim, do uso de dispositivos para avaliar o desempenho como auditorias e surveys (Urbinati e Warren, 2008, pp. 404-405; Goodin, 2008, pp. 168-174).

11 Devo uma formulação inicial deste argumento a Keck (2004) e Dryzek e Niemeyer (2008), que observaram que os movimentos sociais e as ONGs podem ser mais bem compreendidos como "representantes discursivos". Segundo Keck, ONGs e movimentos sociais "tendem representar posições em vez de populações, ideias em vez de distritos eleitorais" (2004, p. 45). Dryzek e Niemeyer defendem uma "accountability discursiva": "para ser responsivo (accountable) ao discurso (ou discursos) que eles representam, os representantes precisam continuar a comunicar em termos que produza sentido dentro deste discurso (ou discursos)" (2008, p. 490). A formulação de Goodin sobre a accountability baseada em redes é também útil para desenvolver este tópico. Ele defende um "modelo horizontal" que reconstrói a accountability em ONGs e atores do terceiro setor como "responsividade, obrigação e desejo de comunicar com os outros por intermédio de várias agências" (2008, p. 172). Neste modelo, dá-se um peso substancialmente maior às intenções dos atores, em comparação aos resultados ou às ações, como nos setores do Estado e do mercado.

12 Em muitos casos, os papéis de representação são formalizados com correspondentes expectativas normativas associadas eles. Como alguns autores vêm discutindo, tais papéis são sempre conflituosos, já que há múltiplas formas de entender deveres e responsabilidades e, ainda, diversos modos de exercer accountability, diante das expectativas e das necessidades dos participantes (Mansbridge, 2004; Castiglione e Warren, 2005, p. 18).
13 Diversos autores têm proposto que a representação não eleitoral não precisa pretender representar todos os interesses e desejos da pessoa. Diferentemente dos atores eleitos, tem-se aqui uma margem maior para que a representação seja parcial (Dryzek e Niemeyer, 2008, p. 488; Saward, 2010, p. 93). Nas palavras de Saward, representantes não eleitorais "podem apoiar um sentido de self que se transforma continuamente, livre das tentações presentes nos momentos eleitorais" (p. 93).

14 Deve-se ressaltar que essas experiências diversas de "minipúblicos" possuem uma gama diferenciada de desenhos institucionais, têm critérios variados para seleção dos participantes e propósitos distintos (Fung e Wright, 2003; Gastil e Levine, 2005; Fung, 2007).

15 As chamadas "câmaras de discurso", propostas por Dryzek e Niemayer (2008), são pensadas para reunir pessoas que sustentam rigorosamente diferentes perspectivas de entendimentos, valores, assunções e juízos. A representação discursiva, segundo os autores, aperfeiçoa os mecanismos deliberativos, na medida em que todas as perspectivas podem ser representadas de modo mais ou menos igualitário (independentemente do número de pessoas que as sustentam). Segundo eles, todas as proposiçôes podem ser contestadas sob uma variedade de pontos de vista, a partir da representação de visões contrapostas deste o início do debate. Em sua palavras, a representação discursiva permite que as decisões políticas, no centro do sistema político, se tornem mais "congruentes com a constelação de discursos existentes na esfera pública” (2008, p. 484).

16 Como Robert Gooding propõe, "a accountability democrática [...] torna-se menos problemática se nós a reconceituamos em termos mais amplos, não eleitorais, englobando accountability em redes, ao invés de accountability dirigida meramente a eleitores empoderados" (2008, p. 155).

\section{BIBLIOGRAFIA}

ABERS, Rebecca N. \& KECK, Margaret. (2008), "Representando a diversidade: Estado, sociedade e 'relações fecundas' nos conselhos gestores”. Caderno CRH, 21 (52): 99-112.

ALEXANDER, Jeffrey. (2006), The civil sphere. Nova York, Oxford University Press.

ANDERSON, Joel \& HONNETH, Axel. (2005), "Autonomy, vulnerability, recognition and justice", in J. Chistiman e J. Anderson (orgs.), 
Autonomy and challenges to liberalism: news essays, Nova York, Cambridge University Press, pp.127-149.

AVRITZER, Leonardo. (2007), "Sociedade civil, instituições participativas e representação: da autorização à legitimidade da ação". Dados, 50 (3): 443-476.

. (2009), Participatory institutions in democratic Brazil. Baltimore, The Johns Hopkins University Press.

BAIOCCHI, Gianpaolo. (2005), Militants and citizens: the politics of participatory democracy in Porto Alegre. Stanford, Stanford University Press.

BENHABIB, Seyla. (2002), The claims of culture: equality and diversity in the global era. Princeton, Princeton University Press.

BOHMAN, James. (2007a), Democracy across borders: from Dêmos to Dêmoi. Cambridge, The MIT Press.

. (2007b), "Beyond distributive justice and struggles for recognition: freedom, democracy and critical theory". European Journal of Political Theory, 6 (3): 267-276.

CASTIGLIONE, Dario \& WARREN, Mark E. (2005), "Rethinking representation: seven theoretical issues". Trabalho apresentado na Midwest Political Science Association Annual Conference, Chicago.

COElHO, Vera S.; POZZONI, Barbara \& MONTOYA, Mariana C. (2005), "Participation and public policies in Brazil”, in J. Gastil e P. Levine (eds.), The deliberative democracy handbook: strategies for effective civic engagement in the 21st Century, São Francisco, Jossey-Bass.

DAHL, Robert. (1998), On democracy. New Haven, Yale University Press.

DOVI, Suzanne. (2002), "Preferable descriptive representatives: will just any woman, black, or Latino do?". American Political Science Review, 96: 729-743.

DRYZEK, J. S. (2010), Foundations and frontiers of deliberative governance. Nova York, Oxford University Press.

DRYZEK, John S. \& NIEMEYER, Simon. (2008), "Discursive representation". American Political Science Review, 102 (4): 481-493.

FELDMAN, Leonard C. (2002), "Redistribution, recognition, and the state: the irreducibly political dimension of injustice". Political Theory, 30 (3): 410-440.

FORST, Rainer. (2007), "First things first: redistribution, recognition and justification". European Journal of Political Theory, 6 (3): 291-304.

FRASER, Nancy. (2001), "Recognition without ethics?”. Theory, Culture \& Society, 18 (2-3): 21-42.

. (2003), "Social justice in the age of identity politics: redistribution, recognition, and participation", in N. Fraser e A. Honneth, Redistribution or recognition: a political-philosophical exchange, Londres/Nova York, Verso, pp. 7-109.

. (2007), "Identity, exclusion, and critique: a response to four critics". European Journal of Political Theory, 6 (3): 305-338.

FUNG, Archon. (2004), Empowered participation: reinventing urban democracy. Oxford, Princeton University Press.

. (2007), "Minipublics: deliberative designs and their consequences", in S. Rosenberg (org.), Can people govern? Deliberation, participation and democracy, Nova York, Palgrave, pp. 159-183.

FUNG, Archon \& WRIGHT, Erik O. (orgs.). (2003), Deepening democracy. Londres, Verso.

GARCÊS, Regiane L. \& MAIA, Rousiley C. M. (2009), "The struggle for recognition of the deaf on the internet: the political function of storytelling". Communication, Politics and Culture, 42: 45-64.

GASTIL, John \& LEVINE, Peter (org.). (2005), The deliberative democracy handbook: strategies for effective civic engagement in the 21st Century. São Francisco, Jossey-Bass.

GOODIN, Robert. (2008), Innovating democracy: democratic theory and practice after the deliberative turn, Oxford, Oxford University Press.

GUTMANN, Amy. (2003), Identity in democracy. Princeton, Princeton University Press.

GUTMANN, Amy \& THOMPSON, Dennis. (2004), Why deliberative democracy? Princeton, Princeton University Press.

HABERMAS, Jürgen. (1993), Justification and application: remarks on discourse ethics. Cambridge, The MIT Press. 
. (1997), Direito e democracia: entre facticidade e validade. Rio de Janeiro, Tempo Brasileiro. . (2006), "Political communication in media society: does democracy still enjoy an epistemic dimension? The impact of normative theory on empirical research". Communication Theory, 16: 411-426.

HOBSON, Bárbara (ed.). (2003), Recognition struggles and social movements: contested identities, agency and power. Cambridge, Cambridge University Press.

HONNETH, Axel. (1995), The struggle for recognition: the moral grammar of social conflicts. Cambridge, MIT Press.

. (2003), "Redistribution as recognition: a response to Nancy Fraser. The point of recognition: a rejoinder to the rejoinder", in N. Fraser e A. Honneth, Redistribution or recognition: a political-philosophical exchange, Nova York, Verso. 110-197.

KECK, Margareth E. (2004), "Governance regimes and the politics of discursive representation" in A. Uhlin e N. Piper (eds.), Transnational activism in Asia: problems of power and democracy, Londres, Routledge. pp. 43-60.

KOMPRIDIS, Nicolas. (2007), "Struggling over the meaning of recognition: a matter of identity, justice or freedom”. European Journal of Political Theory, 6 (3): 277-289.

LAVALLE, Adrián G.; HOUTZAGER, Peter P. \& CASTELLO, G. (2006), "Representação política e organizações civis: novas instâncias de mediação e os desafios da legitimidade". Lua Nova, 67: 59-66.

LOUREIRO, Maria Rita. (2009), "Interpretaçôes contemporâneas da representação”. Revista Brasileira de Ciência Política, 1: 63-94.

MAIA, Rousiley Celi Moreira. (2008), Midia e deliberação. Rio de Janeiro, Editora da FGV.

MAIA, Rousiley Celi Moreira \& FERNANDES, Adélia Barroso. (2002), "O movimento antimanicomial como agente discursivo na esfera pública política”. Revista Brasileira de Ciências Sociais, 17 (48): 157-172.

MANSBRIDGE, Jane. (2003), "Rethinking representation”. American Political Science Review, 97: 515-528.
(2004), "Representation revisited: introduction to the case against electoral accountability". Democracy and Society, 2 (1): 12-13.

McBRIDE, C. (2005), "Deliberative democracy and the politics of recognition". Political Studies, 53: 497-515.

MELUCCI, Alberto. (1996), Challenging codes: collective action in the information age. Cambridge, Cambridge University Press.

. (2001), A invenção do presente: movimentos sociais nas sociedades complexas. Petrópolis, Vozes.

MENDONÇA, Ricardo Fabrino. (2008), "Representation and deliberation in civil society". Brazilian Political Science Review, 2: 117-137.

PARKINSON, J. (2006) Deliberating in the real world: problems of legitimacy in deliberative democracy. Oxford: Oxford University Press.

PETERS, Bernhard. (2007), "The functional capacity of contemporary public spheres", in $\mathrm{H}$. Wessler (ed.), Public deliberation and public culture: the writings of Bernhard Peters, 19932005, Nova York, Palgrave, pp. 121-133.

PHILIPS, Anne. (1995), The politics of presence. Oxford, Oxford University Press.

PINTO, Céli R. J. (2008), "Nota sobre a controvérsia entre Fraser-Honneth informada pelo contexto brasileiro". Lua Nova, 74: 35-58.

PITKIN, Hanna. (1967), The concept of representation. Berkeley, University of California Press. . (2006), "Representação: palavras, representação e ideias”. Lua Nova, 67: 15-47.

REHFELD, Andrew. (2009), "Representation rethought: on trustees, delegates and gyroscopes in the study of political representation and democracy". American Political Science Review, 103 (2): 214-230.

SAWARD, Michael. (2006), "The representative claim”. Contemporary Political Theory, 5: 297 318.

. (2009), "Authorization and authenticity: representation and the unelected". The Journal of Political Philosophy, 17 (1): 1-22.

. (2010), The representative claim. Nova York, Oxford University Press.

SCHERER-WARREN, Ilse. (1996), Redes de movimentos sociais. São Paulo, Edições Loyola. 
SEN, Amartya. (1999), Development as freedom. Nova York, Knopf.

SOUZA, Jessé. (2006), A invisibilidade da desigualdade brasileira. Belo Horizonte, Editora da UFMG.

TAYLOR, Charles. (1994), "The politics of recognition", in A. Gutmann (ed.), Multiculturalism, Princeton, Princeton University Press, pp. 25-73.

THOMPSON, Simon. (2005), "Is redistribution a form of recognition? Comments on the Fraser-Honneth debate". Critical Review of International and Political Philosophy, 8 (1): 85-102. . (2006), The political theory of recognition. Cambridge, Polity Press.

TOURAINE, A. (1978), Le retourn de l'acteur. Paris, Seuil.

TULLY, James. (2000), "Struggles over recognition and distribution". Constellations, 7 (4): 469482.

URBINATI, Nadia. (2000), "Representation as advocacy: a study of democratic deliberation". Political Theory, 28 (6): 758-786. . (2006A), Representative democracy: principles and genealogy. Chicago, The University of Chicago Press. . (2006B), "O que torna a representação democrática?”. Lua Nova, 67: 191-228.

URBINATI, Nadia \& WARREN, Mark E. (2008), "The concept representation in contemporary democratic theory". The Annual Review Political Science, 11: 387-412.

WAMPLER, Brian \& AVRITZER, Leonardo. (2004), "Públicos participativos: sociedade civil e novas instituições no Brasil democrático", in V. S. P. Coelho \& M. Nobre (orgs.), Deliberação e participação: teoria democrática e experiências institucionais no Brasil contemporâneo, São Paulo, Editora 34.

WARREN, Mark E. (2001), Democracy and association. Princeton, Princeton University Press. . (2007). "Institutionalizing deliberative democracy", in S. W. Rosenberg, Can the people govern? Deliberation, participation and democracy, Nova York, Palgrave, pp. 272-310. . (2008), "Citizen representatives", in M. Warren e H. Pearse (eds.), Designing delibe- rative democracy: the British Columbia Citizens' Assembly. Cambridge, UK, Cambridge University Press, pp. 50-69.

YOUNG, Iris Marion. (1990), Justice and the politics of difference. Princeton, Princeton University Press.

(2000), Inclusion and democracy. Oxford, Oxford University Press.

ZURN, Christopher. (2003), "Identity or status? Struggles over recognition in Fraser, Honneth and Taylor". Constellations, 10 (4): 519-537. 


\section{REPRESENTAÇÃO POLÍTICA DE ATORES CIIVICOS: ENTRE A EXPERIÊNCIA E DISCURSOS DE JUSTIFICAÇÃO}

\section{Rousiley Maia}

Palavras-chave: Representação; Sociedade civil; Esfera pública; Associativismo.

Este artigo tem como objetivo explorar o problema da construção da legitimidade da representação na esfera civil, destacando, com base na teoria do reconhecimento, a importância da experiência para uma identificação bem-sucedida de diferentes formas de injustiça. Discute-se, em primeiro lugar, que a experiência subjetiva, apesar de constituir uma fonte insubstituível e necessária de inteligibilidade da injustiça, não pode se tornar uma fonte confiável de justificação na esfera pública. Em segundo, analisam-se diversas formas de representação que se sobrepõem na esfera civil e a necessidade de articulá-las com a representação eleitoral e com os canais tradicionais da política. Nesse sentido, o artigo propõe algumas maneiras de institucionalizar a representação derivada da participação da sociedade civil, a fim de gerar efeitos democráticos na organização da vida social.

\section{POLITICAL REPRESENTATION OF CIVIC ACTORS: BETWEEN THE EXPERIENCE AND DISCOURSES OF JUSTIFICATION}

\author{
Rousiley Maia
}

Keywords: Representation; Civil society; Public sphere; Associativism.

This article investigates the legitimacy building process concerning the representation in the civil society. Based on the recognition theory, the author defends the importance of the subjective experiences for a well-succeeded identification of different forms of injustice. Firstly, the author contends that the subjective experience, although being regarded as a necessary and irreplaceable source of intelligibility of injustice, cannot become a reliable source of justification in the public sphere. Secondly, the author investigates different forms of representation which become overlapped in the civil sphere and the need to articulate them with electoral representation and traditional dynamics of representative politics. Finally, the author discusses some manner to institutionalize the representation coming from civil society participation, in order to produce democratic effects in the organization of social life.

\section{REPRÉSENTATION POLITIQUE DES ACTEURS CIVIQUES : ENTRE L'EXPÉRIENCE ET LE DISCOURS DE JUSTIFICATION}

Rousiley Maia

Mots-clés: Représentation; Société civile; Sphère publique; Formes d'association sociale.

Cet article a pour but d'explorer le problème de la construction de la légitimité de la représentation dans la sphère civile tout en soulignant, en s'appuyant sur la théorie de la reconnaissance, l'importance de l'expérience pour une identification bien succédée des différentes formes d'injustice. Nous proposons, dans un premier lieu, que l'expérience subjective, bien que représentant une source irremplaçable et nécessaire d'intelligibilité de l'injustice, ne peut devenir une source fiable de justification dans la sphère publique. Ensuite, nous analysons les diverses formes de représentation qui se superposent dans la sphère civile, ainsi que la nécessité de les articuler avec la représentation électorale et les canaux traditionnels de la politique. Ainsi, l'article propose quelques manières d'institutionnaliser la représentation dérivée de la participation de la société civile afin de générer des effets démocratiques dans l'organisation de la vie sociale. 